\title{
OPHTHALMOLOGIC ABNORMALITIES IN CHILDREN WITH IMPAIRED HEARING
}

Inderjit Kaur ${ }^{1}$, Jagdeepak Singh ${ }^{2}$, Prempal Kaur ${ }^{3}$, Anup Narayanrao Thakare ${ }^{4}$

\section{HOW TO CITE THIS ARTICLE:}

Inderjit Kaur, Jagdeepak Singh, Prempal Kaur, Anup Narayanrao Thakare. "Ophthalmologic Abnormalities in Children with Impaired Hearing". Journal of Evolution of Medical and Dental Sciences 2014; Vol. 3, Issue 08, February 24; Page: 2008-2015, DOI: 10.14260/jemds/2014/2096

ABSTRACT: AIM: To determine the nature of ophthalmologic abnormalities in severe and profound grades of hearing impaired children and to treat visual impairment if any at the earliest. MATERIAL AND METHODS: Study was conducted on100 children in the age group of 5-14 years with severe and profound hearing loss visiting outpatient department of Ram Lal Eye and ENT hospital Govt. Medical College Amritsar and subjected to detailed ophthalmological examination. RESULTS: 100 children in the age group 5-14 years with hearing impairment were enrolled for the study, 68 had profound and 32 had severe hearing loss. Visual disorders were found to be as high as $71 \%$. Highest percentage was seen in children aged 7 years. Majority of them (50\%) had refractive error. Out of these 50 children, 28(56\%) had myopia, 10 (20\%) hypermetropia and 12(24\%) had astigmatism. The other ophthalmic abnormalities in our study were conjunctivitis $14(19.71 \%)$, fundus abnormalities and squint 11(15.49\%), blepharitis 5 (7.04\%), vitamin A deficiency 6 (8.04\%), amblyopia 8 (11.26\%), pupil disorder 3 (4.22\%), cataract $3(4.22 \%)$ and heterochromia iridis 7 (9.85\%). CONCLUSION: The high prevalence of ophthalmic abnormalities in deaf children mandate screening them for possible ophthalmic abnormalities. Early diagnosis and correction of visual disturbances would go a long way in social and professional performance of these children.

KEYWORDS: Ophthalmologic abnormalities, children, impaired hearing.

INTRODUCTION: Deaf children are heavily reliant on the sense of vision in order to develop efficient communication skills and explore the world around them. Any ophthalmic disorder may thus negatively impact on this process, especially if it is unrecognized in the early years of life. These disorders may be correctable (such as myopia) or treatable (such as cataract), and their early identification is of the utmost importance to optimize language development (spoken or sign, or both) and develop social cognition. ${ }^{1}$

Vast majority of knowledge is obtained through the sense of sight and hearing, when one of these is seriously impaired the other is used to compensate. As the degree of impairment increases the role of the remaining senses becomes progressively more significant. ${ }^{2}$ Thus, the deaf population may compensate by making greater use of visual perceptual clues than their hearing peers and thus even a mild refractive error may reduce the visual clues available to the child. ${ }^{3}$

The control of blindness in children is a VISION 2020 priority because the number of 'blind person years' resulting from blindness starting in childhood is second only to cataract. If VISION 2020 targets for children can be met, the global prevalence of blindness will have fallen from 7.5/10, 000 children (in 1997) to 4/10, 000 children by the year 2020.4

MATERIAL \& METHODS: 100 children, visiting outpatient department of Ram Lal Eye and ENT hospital Govt. Medical College Amritsar between 5 to 14 years with severe and profound hearing loss 
determined by pure tone audiometric/BERA testing, after due consent from the parents and obtaining clearance from the ethical committee were enrolled. History of the risk factors such as history of prematurity or perinatal complications, exposure to ototoxic medications, rubella and cytomegalovirus, neurodevelopmental handicaps and syndromes with known hearing and ophthalmic complications for hearing loss were noted and detailed ophthalmological examination which included, acuity tests, ocular motility tests, a comprehensive ophthalmologic assessment by slit lamp biomicroscopy, streak retinoscopy, direct and indirect ophthalmoscopy, intraocular pressure measurement was done. Children with mild to moderate hearing loss, chronic otitis media and h/o trauma were excluded from the study.

OBSERVATIONS: Out of the 100 children, 32 had severe and 68 had profound hearing loss. 56 were males and 44 were females, with maximum number of children of 7 years age.

\begin{tabular}{|c|c|c|c|}
\hline Age (years) & Male & Female & Total \\
\hline 5 & 7 & 5 & 12 \\
\hline 6 & 11 & 2 & 13 \\
\hline 7 & 8 & 7 & 15 \\
\hline 8 & 2 & 5 & 7 \\
\hline 9 & 4 & 3 & 7 \\
\hline 10 & 5 & 8 & 13 \\
\hline 11 & 4 & 1 & 5 \\
\hline 12 & 4 & 3 & 7 \\
\hline 13 & 5 & 6 & 11 \\
\hline 14 & 6 & 4 & 10 \\
\hline Total & $\mathbf{5 6}$ & $\mathbf{4 4}$ & $\mathbf{1 0 0}$ \\
\hline
\end{tabular}

SHOWING AGE AND SEX DISTRIBUTION OF CHILDREN IN THE STUDY

\begin{tabular}{|c|c|c|c|}
\hline Age (years) & Male & Female & Total \\
\hline 5 & $6(8.45 \%)$ & $4(5.63 \%)$ & $10(14.08 \%)$ \\
\hline 6 & $5(7.04 \%)$ & $2(2.81 \%)$ & $7(9.85 \%)$ \\
\hline 7 & $2(2.81 \%)$ & $7(9.85 \%)$ & $9(12.67 \%)$ \\
\hline 8 & $2(2.81 \%)$ & $4(5.63 \%)$ & $6(8.45 \%)$ \\
\hline 9 & $2(2.81 \%)$ & $2(2.81 \%)$ & $4(5.63 \%)$ \\
\hline 10 & $3(4.22 \%)$ & $6(8.45 \%)$ & $9(12.67 \%)$ \\
\hline 11 & $4(5.63 \%)$ & $0(0.00 \%)$ & $4(5.63 \%)$ \\
\hline 12 & $3(4.22 \%)$ & $2(2.81 \%)$ & $5(7.04 \%)$ \\
\hline 13 & $3(4.22 \%)$ & $6(8.45 \%)$ & $9(12.67 \%)$ \\
\hline 14 & $5(7.04 \%)$ & $3(4.22 \%)$ & $8(11.26 \%)$ \\
\hline Total & $\mathbf{3 5}$ & $\mathbf{3 6}$ & $\mathbf{7 1}$ \\
\hline
\end{tabular}

AGE AND SEX WISE DISTRIBUTION OF CHILDREN WITH VISUAL DISORDERS WITH REGARD TO SEX

Overall prevalence of visual disorder was found to be $71 \%$. 


\begin{tabular}{|c|c|c|c|c|}
\hline Age & Myopia & Hypermetropia & Astigmatism & Total \\
\hline 5 & 3 & 0 & 3 & 6 \\
\hline 6 & 5 & 1 & 0 & 6 \\
\hline 7 & 5 & 0 & 3 & 8 \\
\hline 8 & 0 & 4 & 0 & 4 \\
\hline 9 & 1 & 1 & 1 & 3 \\
\hline 10 & 4 & 2 & 1 & 7 \\
\hline 11 & 2 & 0 & 0 & 2 \\
\hline 12 & 1 & 1 & 2 & 4 \\
\hline 13 & 4 & 1 & 0 & 5 \\
\hline 14 & 3 & 0 & 2 & 5 \\
\hline Total & $\mathbf{2 8}$ & $\mathbf{1 0}$ & $\mathbf{1 2}$ & $\mathbf{5 0}$ \\
\hline \multicolumn{5}{|c|}{ AGE-WISE DISTRIBUTION OF REFRACTIVE ERROR } \\
\hline \multicolumn{5}{|c|}{}
\end{tabular}

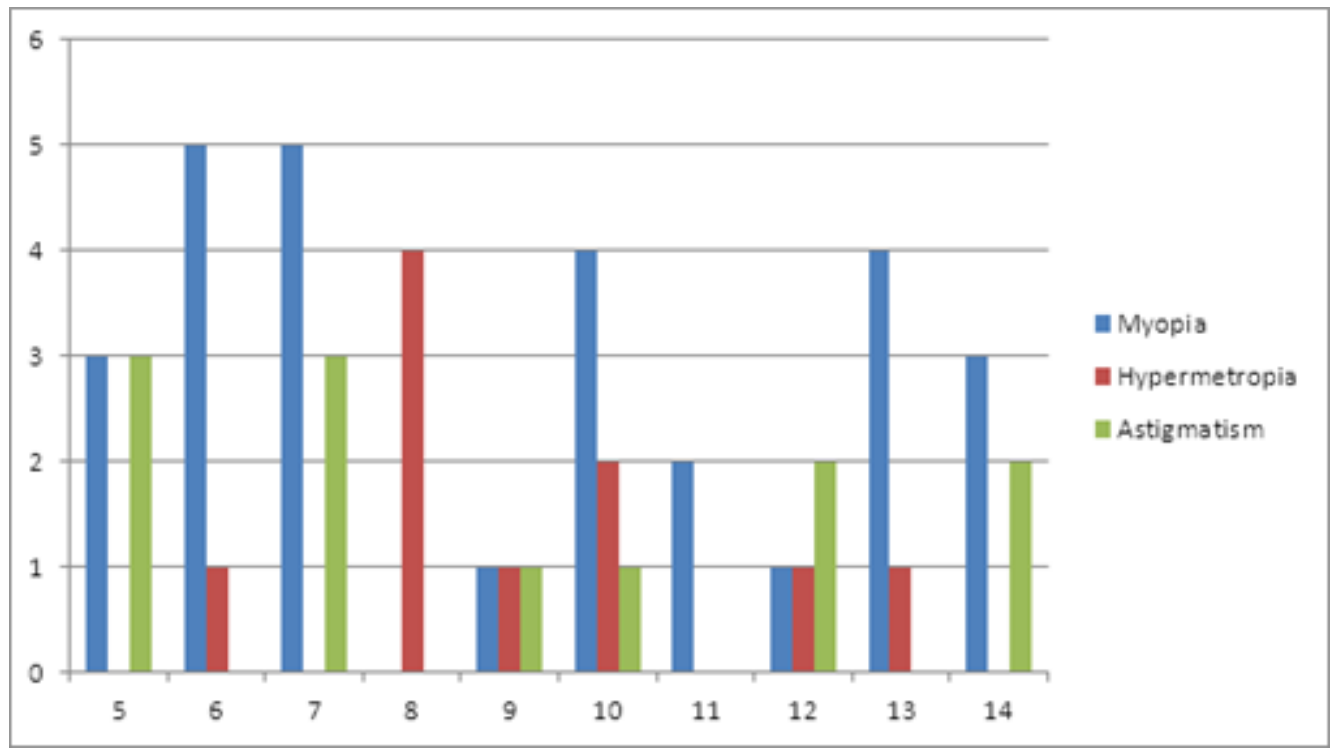

\begin{tabular}{|c|c|c|c|}
\hline Degree of hearing loss & Refractive error & No refractive error & Total \\
\hline Severe & $17(53.12 \%)$ & $15(46.87 \%)$ & 32 \\
\hline Profound & $33(48.52 \%)$ & $35(51.47 \%)$ & 68 \\
\hline Total & $\mathbf{5 0}$ & $\mathbf{5 0}$ & $\mathbf{1 0 0}$ \\
\hline
\end{tabular}

DISTRIBUTION OF REFRACTIVE ERROR WITH RESPECT TO DEGREE OF HEARING LOSS 


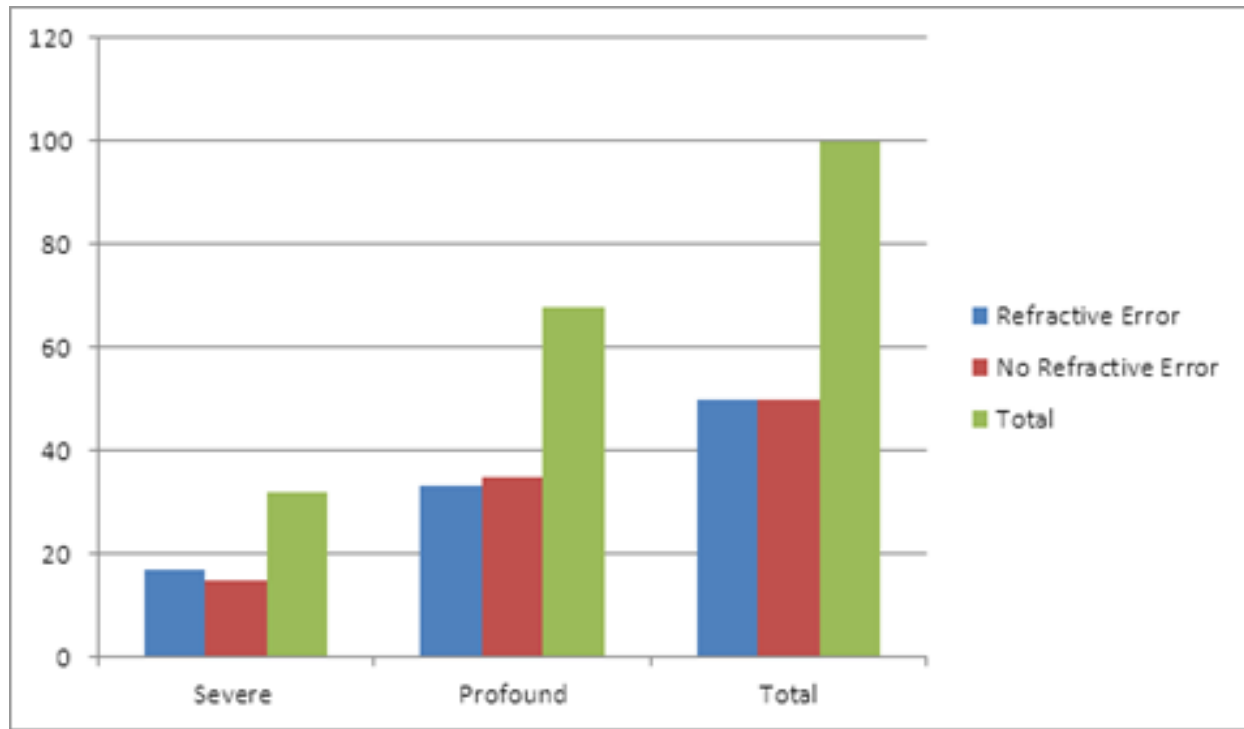

Out of 100 cases in the study majority (50\%) had refractive error. The prevalence of other ophthalmic abnormalities in our study were color vision defect $4(5.63 \%)$, fundus abnormalities $11(15.49 \%)$, cataract $3(4.22 \%)$, squint $11(15.49 \%)$, conjunctivitis $14(19.71 \%)$, blepharitis $5(7.04 \%)$, vitamin A deficiency 6 (8.04\%), amblyopia 8(11.26\%), anisometropia 10(14.08\%), pupil disorder $3(4.22 \%)$, and heterochromia iridis $7(9.85 \%)$.

Some patients had more than one ophthalmic abnormality.

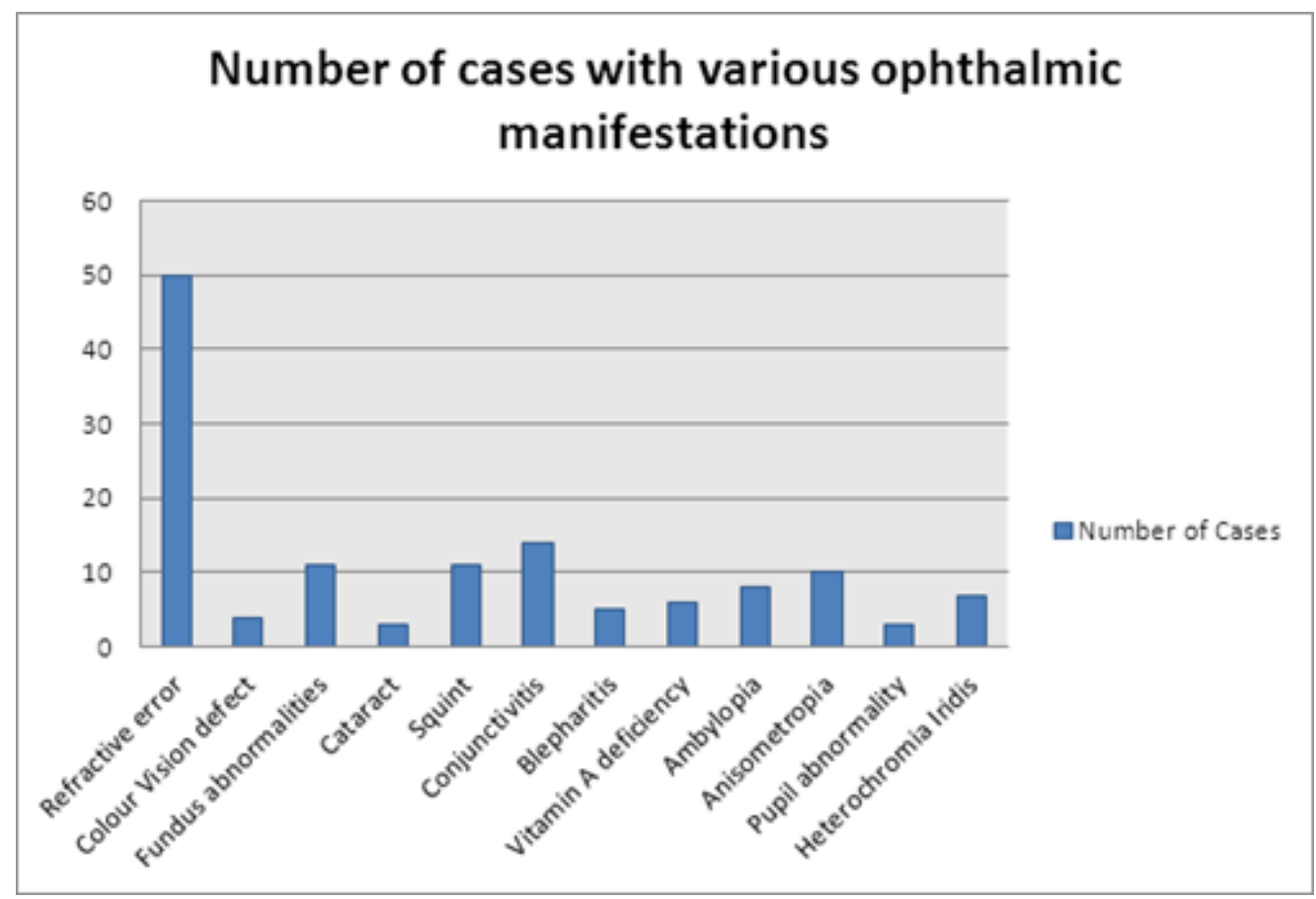




\section{ORIGINAL ARTICLE}

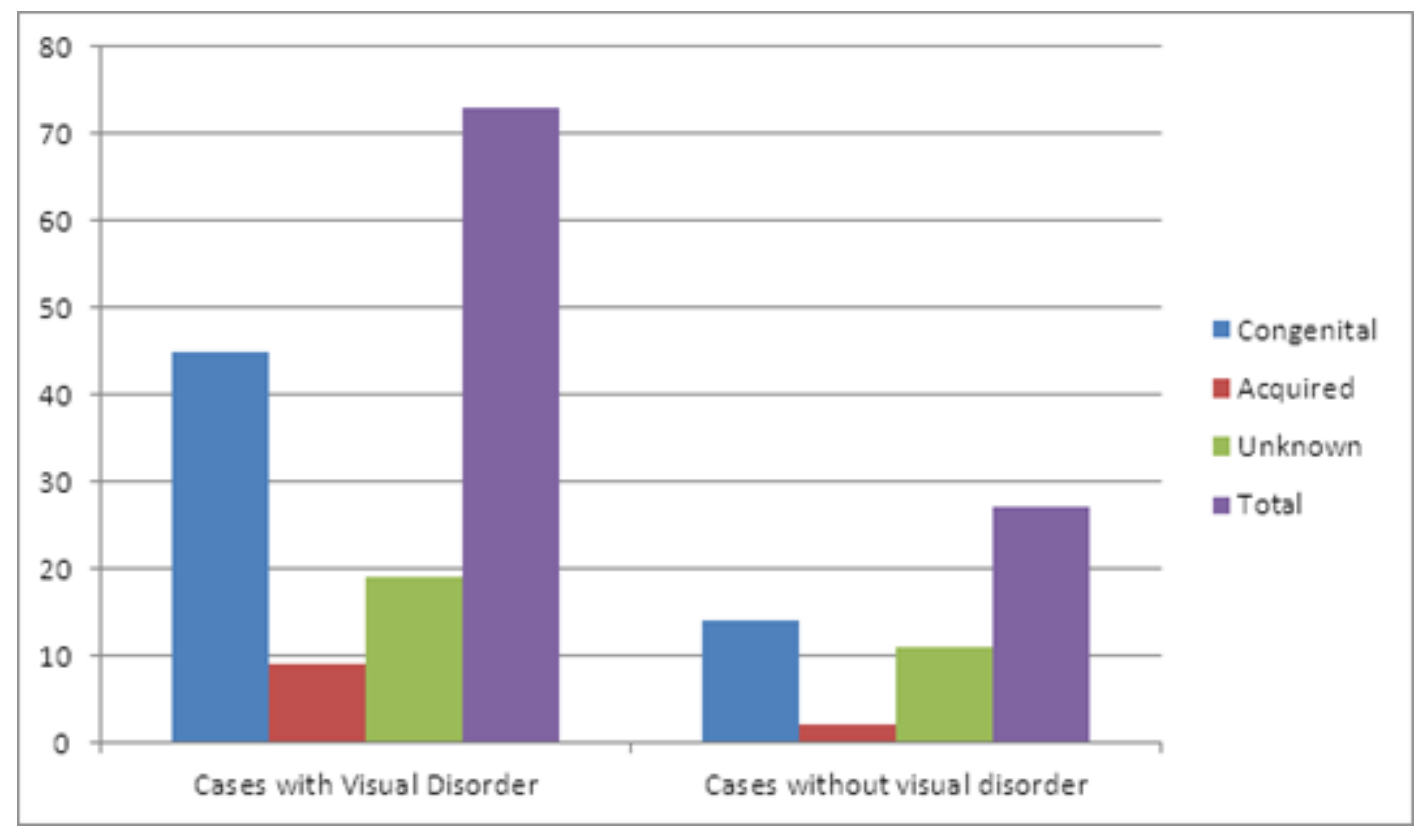

SHOWING DISTRIBUTION OF CASES WITH RESPECT TO ETIOLOGY OF HEARING LOSS

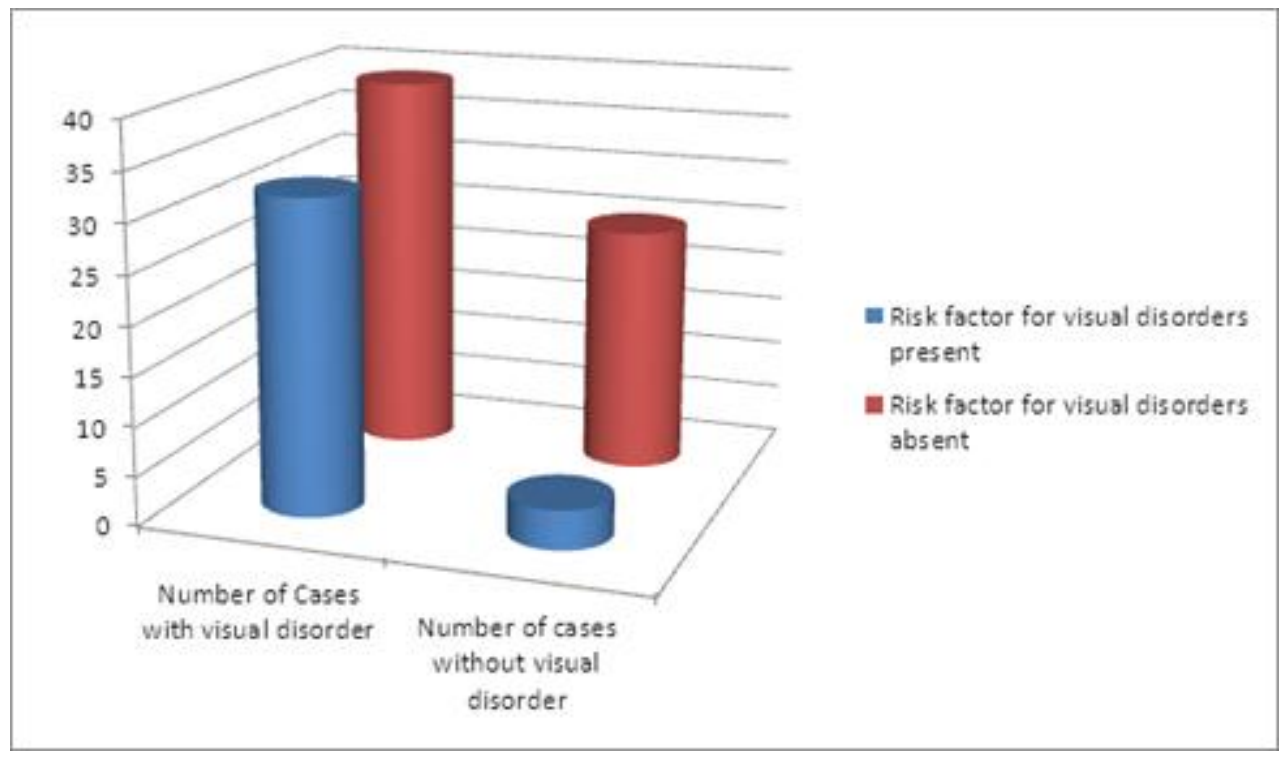

DISTRIBUTION OF CASES WITH RESPECT TO PRESENCE OR ABSENCE OF RISK FACTORS FOR VISUAL DISORDERS 
DISCUSSION: It has been reported that 10 percent of the Indian children below 14 years of age have some kind of an impairment or physical disability which mandates a responsible and effective role of the government and its society. It has been estimated that more than half of the total disabilities are preventable by timely intervention at an early stage 5 . An estimated one to three per 1, 000 children have some degree of sensorineural hearing loss, which occurs as a result of damage to the nerves of the inner ear6. Especially early in life, sensorineural hearing loss is associated with delays in language, speech, cognitive and social development. Given the effects of hearing impairment, children with sensorineural hearing loss are particularly dependent on other means of information acquisition. If these children were to have unrecognized ophthalmologic abnormalities that limited visual acuity, there could be further detrimental effects on development. ${ }^{7}$ The WHO prevention of blindness program with the international center for eye health has developed a standard methodology and reporting firm to record the causes of visual loss in children with emphasis on the identification of treatable or preventable causes of blindness. ${ }^{8}$ Controlling blindness in children is a priority of VISION 2020. ${ }^{9}$ The present study was conducted on 100 children with severe and profound hearing loss in age group of 5 to 14 years. Prevalence of ocular manifestations, their relation to the etiology and degree (severe/profound) of hearing loss with respect to presence or absence of risk factors for visual abnormalities were studied. $71 \%$ of children were affected with some kind of ophthalmologic abnormality. The results of our study correlate well with the following previous studies as shown below in the table.

\begin{tabular}{|l|c|c|c|c|c|}
\hline \multicolumn{1}{|c|}{ Name } & Country & Year & Cases & Ocular problems & Refractive errors \\
\hline Nicol et al $^{10}$ & Australia & 1988 & 78 & $33 \%$ & - \\
\hline Ma et al $^{11}$ & China & 1989 & 279 & $35.8 \%$ & $17.9 \%$ \\
\hline Elango et al $^{12}$ & Malaysia & 1994 & 165 & $57.6 \%$ & $13.9 \%$ \\
\hline Siatkowski et al & USA & 1994 & 54 & $61.1 \%$ & $44.4 \%$ \\
\hline Guy et al $^{14}$ & UK & 2003 & 122 & $90.1 \%$ & $31.1 \%$ \\
\hline Hanioglu-Kargi $^{15}$ & Turkey & 2003 & 104 & $40.4 \%$ & $29.3 \%$ \\
\hline Gogate et al $^{16}$ & India & 2008 & 901 & $24 \%$ & $18.5 \%$ \\
\hline Present study & India & 2011 & 100 & $71 \%$ & $50 \%$ \\
\hline
\end{tabular}

\begin{tabular}{|l|c|}
\hline \multicolumn{1}{|c|}{ STUDY } & PREVALENCE OF OCULAR MORBIDITY \\
\hline Deshpande Jayant D and Malathi $\mathrm{K}^{17}$ & $27.65 \%$ \\
\hline Dandona, Gilbert CE18 & $38 \%$ \\
\hline Madhu Gupta, Bhupinder Gupta $^{19}$ & $31.6 \%$ \\
\hline Khurana AK, Sikka KL ${ }^{20}$ & $58.8 \%$ \\
\hline Desai S, Desai R ${ }^{21}$ & $71.7 \%$ \\
\hline Kalikiyavi V, Naduvilath TJ22 & $43.5 \%$ \\
\hline \multicolumn{2}{|c|}{ PREVALANCE OF OPHTHALMIC ABNORMALITIES } \\
IN SIMILAR STUDIES IN NORMAL CHILDREN
\end{tabular}


Our present study showed a much higher number of ophthalmologic abnormalities i.e. 71\%.as compared to their peers with normal hearing. It was also seen that the prevalence of refractive error was much more in deaf population as compared with normal children of same age group. Refractive error was corrected and suitable glasses were prescribed. Those whose refractive errors could not be corrected had some forms of ocular abnormality such anisometropia, ambylopia, strabismus, pigmentary retinopathy or cataract. An ophthalmologic evaluation is thus of utmost importance in children with hearing loss for the early diagnosis and correction of visual disturbances which would help them in their overall development and performance. Moreover, early notification to the parents about the abnormalities, hereditary syndromes and concomitant co-morbidities would go a long way in the management and rehabilitation of these children. The high prevalence of ophthalmic abnormalities in deaf children, mandate routine ophthalmologic screening for any possible ophthalmologic abnormality.

\section{BIBLIOGRAPHY:}

1. Nikolopoulos TP, Lioumi D, Stamataki S, O'Donoghue GM. Evidence-based overview of ophthalmic disorders in deaf children: a literature update. Otol Neurotol 2006; 27 (2 Suppl 1): S1-24, discussion.

2. Hanioglu-Kargi S, Koksal M, Tomac S, Ugurba SH, Alpay A. Ophthalmologic abnormalities in children from a Turkish school for the deaf. Turk j Pediatr 2003; 45(1):39-42.

3. Murdoch H, Russell-Eggitt I. Visual screening in a school for hearing impaired children. Child Care Health Dev 1990; 16(4):253-61.

4. Gilbert C., Muhit M. Twenty years of childhood blindness: what have we learnt? Comm. Eye Health J. 01 September 2008; 21(67); 46-47. Available from http://www.cehjournal.org/article/twenty-years-of-childhood-blindness-what-have-we-learnt.

5. K.C Pant. A Handbook for Parents of Children with Disabilities.2002 Feb12.p 2.

6. Arun Sharma et al. Arch Otolaryngol Head Neck Surg 2009; 135(2):119-23.

7. Woodruff ME. Differential effects of various causes of deafness on the eyes, refractive errors and vision of children. Am J Optom Physiol Opt 1986; 63:668-75.

8. Gilbert C, Foster A, Negrel AD et al. Childhood blindness: a new form for recording causes of visual loss in children. Bull World Health Organ 1993; 71:485-9.

9. World Health Organization. Global initiative for the elimination of avoidable blindness. WHO/PBL/97.61, Geneva: WHO, 1997.

10. Nicol AM, House P. Ocular abnormalities in deaf children: a discussion of deafness and retinal pigment changes. Aust N Z J Ophthalmol 1988; 16:205-8.

11. Ma QY, Zeng LH, Chen YZ, Li ZY, Guo Xm, Dai Zy, et al. Ocular survey of deaf and mute children. Yan Ke Xue Bao. 1989; 5:44-6.

12. Elango S, Reddy TN, Shriwas SR. Ocular abnormalities in children from a Malaysian school for the deaf. Ann Trop Paediatr 1994; 14:149-52.

13. Siatkowski RM, Flynn JT, Hodges AV, Balkany TJ. Ophthalmologic abnormalities in the pediatric cochlear implant population. Am J Ophthalmol 1994; 118:70-6.

14. Guy R, Nicholson J, Pannu SS, Holden R. A clinical evaluation of ophthalmic assessment in children with sensori-neural deafness. Child Care Health Dev 2003;29:377-84. 
15. Hanioglu-Kargi S, Koksal M, Tomac S, Ugurba SH, Alpay A. Ophthalmologica abnormalities in children from a Turkish school for the deaf. Turk J Pediatric 2003;45:39-42.

16. Gogate P et al. Visual impairment in the hearing impaired students. Indian J Ophthalmol 2009 Nov-Dec;57(6):451-3.

17. Deshpande Jayant D, Malathi K. Prevalence of ocular morbidity among school children in rural area of north Maharashtra in India. National Journal of Community Medicine July-Sept 2011;2(2). P.249.

18. Dandona L, Gilbert CE, Rahi JS, Rao GN. Childhood blindness in India. Indian J Ophthalmology 1998;46:117-22.

19. Madhu Gupta, Bhupinder Gupta, Ocular morbidity prevalence among school children in Shimla, Himachal, North India. Community eye care 2009;57(2):133-8.

20. Khurana AK, Sikka KL, Parmar IPS, Aggarwal SK. Ocular morbidity among school children in Rohtak city. Indian J Public Health 1984;28:217-20.

21. Desai S, Desai R, Desai NC, Lohiya S, Bhargava G, Kumar K. School eye health appraisal. Indian J Ophthalmol 1989;37:173-5.

22. Kalikivayi V, Naduvilath TI, Bansal AK, Dandona L. Visual Impairment in school children in Southern India. Ind J Ophthalmol 1997;45:129-34.

\section{AUTHORS:}

1. Inderjit Kaur

2. Jagdeepak Singh

3. Prempal Kaur

4. Anup Narayanrao Thakare

\section{PARTICULARS OF CONTRIBUTORS:}

1. Associate Professor, Department of Ophthalmology, Regional Institute of Ophthalmology, Amritsar, Punjab.

2. Professor, Department of ENT, Government Medical College, Amritsar, Punjab.

3. Associate Professor, Department of Ophthalmology, Regional Institute of Ophthalmology, Amritsar, Punjab.
4. Post Graduate, Department of Ophthalmology, Regional Institute of Ophthalmology, Amritsar, Punjab.

\section{NAME ADDRESS EMAIL ID OF THE CORRESPONDING AUTHOR:}

Dr. Inderjit Kaur,

20, Doctor's Avenue,

Majitha Road,

Amritsar, Punjab.

E-mail: renudoc@yahoo.com

Date of Submission: 29/01/2014.

Date of Peer Review: 30/01/2014.

Date of Acceptance: 11/02/2014.

Date of Publishing: 21/02/2014. 